\title{
Assessment of E-learning System in Higher Education Based on Hesitant Fuzzy Information with Incomplete Attribute Weights
}

\author{
http://dx.doi.org/10.3991/ijet.v10i8.5217 \\ Hong Ye \\ Dalian Maritime University, Dalian, China
}

\begin{abstract}
With the development of information technology, colleges and universities around the world are constructing E-learning system to meet their students' and faculty's needs. E-learning can effectively help students to learn varieties of knowledge and even skills they want to obtain. Therefore, the efficiency of E-learning system is important to popularize and develop it. Then, in this paper, we investigate to propose a method to evaluate E-learning system in higher education based on some criteria. Hereinto, this assessment problem can be considered as a multiple attribute decision making (MADM) problem. Thus, TOPSIS method, as a popular multiple attribute decision making method, is introduced in this paper to solve this assessment problem. In MADM problem, how to acquire preference of the decision maker is critical. In order to solve this issue, hesitant fuzzy set is developed in this paper. Weight vector, as a balance to weight the importance of different attributes, is hard to obtain. Then, a new fuzzy weight method is proposed to determine attribute weights. Finally, a case study is demonstrated to verify the applicability of this method.
\end{abstract}

Index Terms-E-learning system, hesitant fuzzy set, higher education, multiple attribute decision making, TOPSIS.

\section{INTRODUCTION}

Modern education seeks to find a way to satisfy the demand of students with advanced technology [1]. With enhanced and rapid advancements in technology, numerous innovative services and applications are being developed. E-learning system as a product of the development of advanced technology has been attracted much attention [2-4]. Online education provides students with an educational alternative to face-to-face courses, permitting students to proceed, at their own pace, and to identify their own personal course timeline. Flexibility, interaction, teaching presence, collaborative learning, and a great sense of community are very important categories in online students' discourses [5-6]. E-learning pedagogy allows students to have a more accurate perception of the effectiveness of their own learning, increasing student-toteacher interaction, as well as critical thinking. Interaction among peers, and with teachers, is privileged by elearning students promoting the existence of a learning community and also emphasized the teacher's expertise and role as a facilitator in learning. In sum, it is important for developing E-learning system in higher education.

Therefore, the efficiency of E-learning system is significant to popularize and develop it. Then, in this paper, we investigate to propose a method to evaluate Elearning system in higher education based on some criteria. Hereinto, this assessment problem can be considered as a multiple attribute decision making (MADM) problem. In MADM problem, how to acquire preference of the decision maker is critical. In order to solve this issue, hesitant fuzzy set is developed in this paper [7-8]. In the process of hesitant fuzzy information aggregation, however, it produces the loss of too much information due to the complexity of the aggregation process of hesitant fuzzy aggregation operators, which implies a lack of precision in the final results [9]. Therefore, in order to overcome this disadvantage, TOPSIS method, as a popular multiple attribute decision making method, is introduced in this paper to solve this assessment problem. TOPSIS, proposed by Hwang and Yoon [10], is a kind of method to solve MADM problems, which aims at choosing the alternative with the shortest distance from the positive ideal solution (PIS) and the farthest distance from the negative ideal solution (NIS), and is widely used for tackling the ranking problems in real situations [11-13]. A key step in TOPSIS is the selection of distance measure which is fundamentally important in a variety of scientific fields such as decision pattern recognition, machine learning and market prediction. Lots of studies have been done on this issue [14-16]. In addition, weight vector, as a balance to weight the importance of different attributes, is hard to obtain. Then, a new fuzzy weight method is proposed to determine attribute weights [17-19]. Finally, a numerical example is demonstrated to verify applicable and reasonable of this evaluation method in hesitant fuzzy environment.

The rest of this paper is organized as follows. In Section 2 , we review some concepts of hesitant fuzzy sets. Section 3 proposed the new method including distance measure between two hesitant fuzzy numbers, attribute weights and the process of the proposed method. A case study is demonstrated in Section 4. Finally, Section 5 concludes this paper.

\section{THE RELEVANT CONCEPTS AND MODEL}

In this section, we introduce hesitant fuzzy multiple decision making methods to evaluate performance of Elearning system. Based on the basic concepts of hesitant fuzzy TOPSIS method, we propose a method to solve this problem.

Torra proposed the concept of hesitant fuzzy set which is in terms of a function when applied to a fixed set returns a sunset of $[0,1]$. Then, in order to easily understood, Xia and $\mathrm{Xu}$ [18-19] express the hesitant fuzzy set by mathematical symbol. 
Definition 1[20-21]. Let $X$ be a universe of discourse, then a hesitant fuzzy set $H$ over $X$ is defined as

$$
H=\left\{<x, h_{H}(x)>\mid x \in X\right\}
$$

where $h_{H}(x)$ is a set of some values in $[0,1]$, symbolizing the possible membership degrees of the element $x$ to $H$. For convenience, we call $h=h_{H}(x)$ a hesitant fuzzy element and $H$ the set of all hesitant fuzzy elements.

Definition 2[20-21] Let $h, h_{1}$ and $h_{2}$ be three hesitant fuzzy numbers, their basic operations are defined as

1) $h^{c}=U_{\gamma \in h}\{1-\gamma\}$;

2) $h_{1} \mathrm{U} h_{2}=\mathrm{U}_{\gamma_{1} \in h_{1}, \gamma_{2} \in h_{2}} \max \left\{\gamma_{1}, \gamma_{2}\right\}$;

3) $h_{1} \mathrm{I} h_{2}=\mathrm{U}_{\gamma_{1} \in h_{1}, \gamma_{2} \in h_{2}} \min \left\{\gamma_{1}, \gamma_{2}\right\}$.

Here, $h^{c}$ represents the complement of the hesitant fuzzy number $h$. In addition, Torra ${ }^{[13]}$ defined that the envelopment of a hesitant fuzzy element is an IFV.

Definition 3[20-21] Let $h$, be a hesitant fuzzy number, the IFV $A_{\text {env }}(h)$ as the envelope of $h$, where $A_{\text {env }}(h)$ can be defined as $\left(h^{-}, 1-h^{+}\right)$, with $h^{-}=\min \{\gamma \mid \gamma \in h\}$ and $h^{+}=$ $\max \{\gamma \mid \gamma \in h\}$.

1) $A_{\text {env }}\left(h^{c}\right)=\left(A_{\text {env }}(h)\right)^{c}$;

2) $A_{\text {env }}\left(h_{1} \mathrm{U} h_{2}\right)=A_{\text {env }}\left(h_{1}\right) \cup A_{\text {env }}\left(h_{2}\right)$;

3) $A_{\text {env }}\left(h_{1} \mathrm{I} h_{2}\right)=A_{\text {env }}\left(h_{1}\right) \mathrm{I} A_{\text {env }}\left(h_{2}\right)$;

Then, an aggregation principle for hesitant fuzzy elements is proposed by Torra and Narukawa[7] and Torra[8].

Definition 4 Let $H=\left\{h_{1}, h_{2}, \ldots, h_{n}\right\}$ be a set of $n$ hesitant fuzzy elements, $\Theta$ be a function on $H, \Theta:[0$, $1]^{N} \rightarrow[0,1]$. $\Theta$ can be defined as follow:

$$
\Theta_{E}=\underset{\gamma \in\left\{h_{1} \times h_{2} \times \ldots \times h_{n}\right\}}{U}\{\Theta(\gamma)\}
$$

\section{PROPOSED METHOD WITH HESITANT FUZZY SET}

In this section, a new TOPSIS method will be demonstrated to evaluate the performance of information system in higher education including the determination of attributes weight, the acquirement of distance measure and the process of TOPSIS method.

\section{A. Distance measure}

The Euclidean distance, as a popular distance, is a useful technique for calculating the differences between two parameters, such as problems with two elements or two sets. The Euclidean distance has been widely applied in fuzzy sets, interval-valued fuzzy sets and intuitionistic fuzzy sets.

Definition 5. Let A and B be two hesitant fuzzy sets on $X=\left\{x_{1}, x_{2}, \ldots, x_{n}\right\}$, then the distance measure between A and $\mathrm{B}$ is defined as $d(A, B)$, which satisfies the following properties:

1) Non-negativity $0 \leq d(A, B) \leq 1$;

2) Commutativity $d(A, B)=d(B, A)$;

3) Reflexivity $d(A, B)=0$ if and only if $A=B$.

Generally, in hesitant fuzzy sets, the length of the membership of $h_{1}$ denoted by $l\left(h_{1}\left(x_{i}\right)\right)$ does not mostly equal to that of $h_{2}$ denoted by $l\left(h_{2}\left(x_{i}\right)\right)$. In order to solve this problem, $\mathrm{Xu}$ and $\mathrm{Xia}$ suggested that we should extend the shorter one depending on the decision maker's risk preferences until both of them have the same length. Hereinto, optimists expect desirable results and should add the maximum value, while pessimists anticipate unfavorable outcomes and should add the minimal value. In this paper, we suggest that the decision makers are all pessimistic.

Thus, the Euclidean distance can be defined in the following:

Definition 6. Let $a_{1}$ and $a_{2}$ be two hesitant fuzzy sets on $X=\left\{x_{1}, x_{2}, \ldots, x_{n}\right\}$, then the distance measure between $a_{1}$ and $a_{2}$ is defined as follows:

$$
d\left(a_{1}, a_{2}\right)=\left[\frac{1}{n} \sum_{i=1}^{n}\left(\frac{1}{l_{x_{i}}} \sum_{j=1}^{l_{n}}\left(h_{1}^{\sigma(\mathrm{j})}\left(x_{i}\right)-h_{2}^{\sigma(\mathrm{j})}\left(x_{i}\right)\right)^{2}\right)\right]^{1 / 2}
$$

where $h_{1}^{o(\mathrm{j})}\left(x_{i}\right)$ and $h_{2}^{\sigma(\mathrm{j})}\left(x_{i}\right)$ are the largest values in $h_{1}\left(x_{i}\right)$ and $h_{2}\left(x_{i}\right)$, respectively, which will be applied thereafter.

Example. Let $a_{1}=\{0.2,0.4\}$ and $a_{2}=\{0.3,0.6,0.7\}$ be two hesitant fuzzy sets, then the distance measure between $a_{1}$ and $a_{2}$ is calculated as follows:

Firstly, suppose the preference of decision maker is risk-aversion. So, $a_{1}=\{0.2,0.4\}$ is extended to $a_{1}=\{0.4$, $0.6,0.8\}$. Then, it can be further obtained that

$$
\begin{aligned}
d\left(a_{1}, a_{2}\right) & =1 / 3\left\{(0.2-0.4)^{2}+(0.2-0.6)^{2}+(0.4-0.8)^{2}\right\} \\
& =0.12
\end{aligned}
$$

\section{B. Attribute weights}

To determine the weights of attributes is important for dealing with multiple attribute decision making (MADM) problems (reference). Different weights may result in different ranking order of the alternatives. Generally, the weights can be classified into subjective weights and objective weights depending on the information source (reference). Subjective weights reflect the subjective judgment or intuition of the decision maker, and they can be obtained from the preference information given by the decision make directly through interviews, questionnaires or trade-off interrogations. The most representative method is Analytical Hierarchy Process (AHP), which was proposed by Saaty in 1971 [22-23]. Objective weights are derived from objective information, such as the decision matrix.

In this section, a non-linear programming model will be constructed to determine the weight vector $w$ which maximizes all deviation values for all the attributes as follows:

$$
\left\{\begin{array}{l}
\max D(w)=\sum_{j=1}^{n} \sum_{i=1}^{m} \sum_{k=1}^{m} w_{j} \sqrt{\frac{1}{l} \sum_{\lambda=1}^{l}\left|h_{i j}^{\sigma(\lambda)}-h_{\mathrm{k} j}^{\sigma(\lambda)}\right|^{2}} \\
\text { s.t. } w_{j} \geq 0, j=1,2, \ldots, n, \sum_{j=1}^{n} w_{j}^{2}=1
\end{array}\right.
$$

From this model, we can obtain that

$$
w_{j}=\frac{\sum_{i=1}^{m} \sum_{k=1}^{m} \sqrt{\frac{1}{l} \sum_{\lambda=1}^{l}\left|h_{i j}^{\sigma(\lambda)}-h_{\mathrm{k} j}^{\sigma(\lambda)}\right|^{2}}}{\sqrt{\sum_{j=1}^{n}\left(\sum_{i=1}^{m} \sum_{k=1}^{m} \sqrt{\frac{1}{l} \sum_{\lambda=1}^{l}\left|h_{i j}^{\sigma(\lambda)}-h_{\mathrm{k} j}^{\sigma(\lambda)}\right|^{2}}\right)^{2}}}
$$


In order to simplify, suppose

$$
Y_{j}=\sum_{i=1}^{m} \sum_{k=1}^{m} \sqrt{\frac{1}{l} \sum_{\lambda=1}^{l}\left|h_{i j}^{\sigma(\lambda)}-h_{\mathrm{k} j}^{\sigma(\lambda)}\right|^{2}}, j=1,2, \ldots, n \text {. }
$$

Then, Eq. (5) can be rewritten as:

$$
w_{j}=\frac{Y_{j}}{\sqrt{\sum_{j=1}^{n} Y_{j}^{2}}}, j=1,2, \ldots, n .
$$

Based on the Eq. (6), the weights of different attributes can be obtained in the process of solving the decision making problems

\section{Process of proposed method}

In this section, we will propose a procedure to form this evaluation model based on mentioned methods, where values take the form of hesitant fuzzy numbers. The procedure includes the following steps:

Step1. For a evaluation problem, we construct a decision matrix $H=\left[\mathscr{H}_{i j}\right]_{m ¥ n}$, where all the arguments $\%_{i j}(i$ $=1,2, \ldots, m ; j=1,2, \ldots, n)$ are hesitant fuzzy numbers, given by the decision maker. As for every alternative $A_{i}$ $(i=1,2, \ldots, m)$, the decision maker is invited to express evaluation or preference according to each attribute $C_{j}(j$ $=1,2, \ldots, n)$ by a hesitant fuzzy number $h_{i j}(i=1,2, \ldots, m$; $j=1,2, \ldots, n)$. Then, based on the risk preference of decision maker, a normal decision making matrix can be obtained as follows:

$$
H_{m \times n}=\left(\begin{array}{cccc}
\tilde{h}_{11} & \tilde{h}_{12} & \cdots & \tilde{h}_{1 n} \\
\tilde{h}_{21} & \tilde{h}_{22} & \cdots & \tilde{h}_{2 n} \\
\vdots & \vdots & \ddots & \vdots \\
\tilde{h}_{m 1} & \tilde{h}_{m 2} & \cdots & \tilde{h}_{m n}
\end{array}\right)
$$

Step 2. The hesitant fuzzy positive ideal solution PIS denoted as $A^{+}$and the hesitant fuzzy negative ideal solution NIS denoted as $A^{-}$can be defined as

$$
\begin{gathered}
A^{+}=\left\{x_{j}, \max _{i}\left\langle h_{i j}^{\sigma(\lambda)}\right\rangle \mid j=1,2, \ldots, n\right\}, \\
A^{-}=\left\{x_{j}, \min _{i}\left\langle h_{i j}^{\sigma(\lambda)}\right\rangle \mid j=1,2, \ldots, n\right\} .
\end{gathered}
$$

Step 3. The attribute weights of the $n$ attributes denoted as $w=\left(w_{1}, w_{2}, \ldots, w_{n}\right)^{T}$ with $0 \leq w_{j} \leq 1(j=1,2, \ldots, n)$ and $\sum_{i=1}^{n} w_{j}=1$ can be determined by Eqs.(4)-(5).

Step 4. The separation between alternatives in hesitant fuzzy context can be measured by Euclidean distance in Eq. (3).

Step 5. The relative closeness coefficient of an alternative with respect to the hesitant fuzzy PIS is defined as

$$
C_{i}=\frac{d\left(h_{i j}, A^{+}\right)}{d\left(h_{i j}, A^{+}\right)+d\left(h_{i j}, A^{-}\right)} .
$$

Here, $d\left(h_{i j}, A^{+}\right)=\sum_{j=1}^{n} w_{j}\left[\frac{1}{l} \sum_{\lambda=1}^{l}\left(h_{i j}^{\sigma(\lambda)}-\left(h_{j}^{\sigma(\lambda)}\right)^{+}\right)^{2}\right]^{1 / 2}$,

$d\left(h_{i j}, A^{-}\right)=\sum_{j=1}^{n} w_{j}\left[\frac{1}{l} \sum_{\lambda=1}^{l}\left(h_{i j}^{\sigma(\lambda)}-\left(h_{j}^{\sigma(\lambda)}\right)^{-}\right)^{2}\right]^{1 / 2}, i=1,2, \ldots, n$.
Step 6. The rank-order can be obtained using Step 5 Then, we can select optimal alternative by the largest score.

Step 7. End.

\section{CASE STUDY}

The evaluation model of E-learning system will be demonstrated in this section with the proposed method in this paper under hesitant fuzzy environment.

In order to verify the proposed evaluation methods, we invite a famous expert as the decision maker to implement process of decision making. Three companies which provide E-learning system are selected by the decision maker as the alternatives including $A_{1}, A_{2}$, and $A_{3}$. Then, the decision maker identifies three attributes denoted as learning quality $C_{1}$, satisfaction and interaction $C_{2}$, and technological levels $C_{3}$ demonstrated.

TABLE I.

THE EXPLANATION OF ATTRIBUTES

\begin{tabular}{|l|l|}
\hline & \multicolumn{1}{|c|}{ Meaning } \\
\hline$C_{1}$ & learning quality \\
\hline$C_{2}$ & satisfaction and interaction \\
\hline$C_{3}$ & technological levels \\
\hline
\end{tabular}

The decision maker gives preference of each alternative on each attribute, respectively. Therefore, a hesitant fuzzy decision matrix $H=\left[h_{i j}\right]_{3 ¥ 3}$ can be illustrated in Table 2 .

TABLE II.

ORIGINAL HESITANT FUZZY DECISION MATRIX

\begin{tabular}{|l|l|l|l|}
\hline & \multicolumn{1}{|c|}{$\boldsymbol{A}_{\mathbf{1}}$} & \multicolumn{1}{c|}{$\boldsymbol{A}_{\mathbf{2}}$} & \multicolumn{1}{c|}{$\boldsymbol{A}_{\mathbf{3}}$} \\
\hline$C_{1}$ & $\{0.4,0.5\}$ & $\{0.1,0.3\}$ & $\{0.5,0.6\}$ \\
\hline$C_{2}$ & $\{0.5,0.7\}$ & $\{0.4,0.5,0.7\}$ & $\{0.2,0.3\}$ \\
\hline$C_{3}$ & $\{0.2\}$, & $\{0.2,0.3,0.6\}$ & $\{0.3,0.4,0.5\}$ \\
\hline
\end{tabular}

It can be obtained that the decision maker is riskaversion by interviewing with him. Therefore, the normal decision matrix can be acquired in Table 3. Then, the decision maker can be obtained that the attribute weights of these three attributes denoted as $w=(0.5,0.2,0.3)^{T}$ based on the Eq. (6).

Based on the Step 4 in the process of decision making, it can be calculated that the distance between the each alternative and positive ideal solution. Meanwhile, the distance between the each alternative and negative ideal solution could be also computed. Finally, using Step 5, combining the distance measure between each alternative and positive ideal solution and negative ideal solution, the closeness coefficient can be acquired in Figure 1. Then, the rank of this assessment problem is demonstrated as $A_{3}$ f $A_{1} \mathrm{f} \quad A_{2}$ from Table 4 and Figure 1 From the ranking order, we can select that $A_{3}$ is the best choice to provide Elearning system.

\section{CONCLUSIONS}

With enhanced and rapid advancements in technology, numerous innovative services and applications are being developed. E-learning system as a product of the development of advanced technology has been attracted much attention. Therefore, the efficiency of E-learning 
system is important to popularize and develop it. Then, in this paper, we propose a new TOPSIS method to evaluate E-learning system in higher education based on some criteria. Here, how to acquire preference of the decision maker is critical. In order to solve this issue, hesitant fuzzy set is developed in this paper. Weight vector, as a balance to weight the importance of different attributes, is hard to obtain. Then, a new fuzzy weight method is proposed to determine attribute weights. Finally, a case study is demonstrated to verify the applicability of this method.

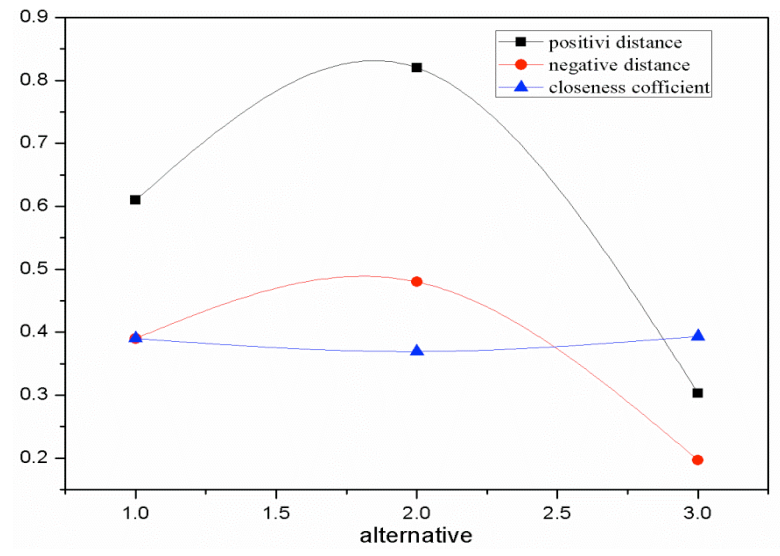

Figure 1. Closeness coefficient of each alternative

TABLE III. NORMAL HESITANT FUZZY DECISION MATRIX

\begin{tabular}{|l|c|c|c|}
\hline & $\boldsymbol{A}_{\mathbf{1}}$ & $\boldsymbol{A}_{\mathbf{2}}$ & $\boldsymbol{A}_{\mathbf{3}}$ \\
\hline$C_{1}$ & $\{0.4,0.5,0.4\}$ & $\{0.1,0.3,0.1\}$ & $\{0.5,0.6,0.5\}$ \\
\hline$C_{2}$ & $\{0.5,0.7,0.5\}$ & $\{0.4,0.5,0.7\}$ & $\{0.2,0.3,0.2\}$ \\
\hline$C_{3}$ & $\{0.2,0.2,0.2\}$ & $\{0.2,0.3,0.6\}$ & $\{0.3,0.4,0.5\}$ \\
\hline
\end{tabular}

TABLE IV. SCORES AND RANK BASED ON HFAWA

\begin{tabular}{|l|l|l|}
\hline & \multicolumn{1}{|c|}{ score } & \multicolumn{1}{c|}{ rank } \\
\hline$A_{1}$ & 0.39 & 2 \\
\hline$A_{2}$ & 0.36923 & 3 \\
\hline$A_{3}$ & 0.39334 & 1 \\
\hline
\end{tabular}

\section{REFERENCES}

[1] U.M. Azeiteiro, P. Bacelar-Nicolau, F.J.P. Caetano. Education for sustainable development through e-learning in higher education: experiences from Portugal, Journal of Cleaner Production. 106 (2015): 308-319. http://dx.doi.org/10.1016/j.jclepro.2014.11.056

[2] A.K.M. Najmul Islam. E-learning system use and its outcomes: Moderating role of perceived compatibility, Telematics and Informatics. 33 (2006): 48-55. http://dx.doi.org/10.1016/ j.tele.2015.06.010

[3] P. Blistan, L. Kovanic, M. Kovanicova. The importance of geographic information systems education at universities in the process of building a European knowledge-based society, Procedia social and behavioral sciences, 191 (2015): 2458-2462. http://dx.doi.org/10.1016/j.sbspro.2015.04.358

[4] I.T. Awidi, M. Cooper. Using management procedure gaps to enhance e-learning implementation in Africa, Computers \& Education. 90 (2015): 64-79. http://dx.doi.org/10.1016/j.compedu. 2015.08.003

[5] N. J. Navimipour, B. Zareie. A model for assessing the impact of e-learning systems on employees' satisfaction, Computers in Human Behavior. 53 (2015): 475-485. http://dx.doi.org/10.1016/ j.chb.2015.07.026

[6] J. Stoffregen, J.M. Pawlowski, H. Pirkkalainen, A barrier framework for open e-learning in public adminstrations, Computers in Human Behavior. 51 (2015): 674-684. http://dx.doi.org/10.1016/ j.chb.2014.12.024
[7] V. Torra, Y. Narukawa. on hesitant fuzzy sets and decision. 2009 IEEE International Conference on Fuzzy Systems. 2009(3): 13781382. http://dx.doi.org/10.1109/FUZZY.2009.5276884

[8] [8] V. Torra. Hesitant fuzzy sets. International Journal of Intelligent Systems 25(6)(2010): 225-235.

[9] Z.S. Xu, X.L. Zhang. Hesitant fuzzy multi-attribute decision making based on TOPSIS with incomplete weight information. Knowledge-Based Systems 52(2013): 53-64. http://dx.doi.org/ 10.1016/j.knosys.2013.05.011

[10] C.L. Hwang, K. Yoon, Multiple Decision Making Methods and Applications. Berlin, Germany: Springer (1981). http://dx.doi.org/ 10.1007/978-3-642-48318-9

[11] R.A. Krohling, R. Lourenzutti, M. Campos, Ranking and comparing evolutionary algorithms with Hellinger-TOPSIS, Applied Soft Computing. 37 (2015): 217-226. http://dx.doi.org/10.1016/ j.asoc.2015.08.012

[12] T. W. Liao, Two interval type 2 fuzzy TOPSIS material selection methods, Materials \& Design, 88 (2015): 1088-1099. http://dx.doi.org/10.1016/j.matdes.2015.09.113

[13] F. Ye, Y. Li, An extended TOPSIS model based on the possibility theory under fuzzy environment, Knowledge-based systems. 67 (2014): 263-269. http://dx.doi.org/10.1016/j.knosys.2014.04.046

[14] Z.S. Xu, M. M. Xia. Distance and similarity measures for hesitant fuzzy sets, Information Sciences, 2011(181), 2128-2138. http://dx.doi.org/10.1016/j.ins.2011.01.028

[15] I. Aguilo, J. Martin, G. Mayor, J. Surier, On distances derived from t-norms, Fuzzy sets and Systems, 278(1) (2015): 40-47. http://dx.doi.org/10.1016/j.fss.2014.09.021

[16] J.C. Figueroe-Garcia, Y. Chalco-Cano, H. Roman-Flores, Distance measures for interval type-2 fuzzy numbers, Discrete Applied Mathematics, 197 (2015): 93-102. http://dx.doi.org/10.1016/ j.dam.2014.11.016

[17] D.H. Peng, C.Y. Gao, Z.F. Gao, Generalized hesitant fuzzy synergetic weighted distance measures and their application to multiple criteria decision-making. Applied Mathematical Modelling. 2013, 37, 5837-5850. http://dx.doi.org/10.1016/j.apm.2012.11.016

[18] M.M. Xia, Z.S. Xu, Hesitant fuzzy information aggregation in decision making, International Journal of Approximate Reasoning. 52 (3) (2011) 395-407. http://dx.doi.org/10.1016/j.ijar.2010. 09.002

[19] L.F. Li, S.Y. Liu, J.K. Zhang, On fuzzy generalized convex mappings and optimality conditions for fuzzy weakly univex mappings, Fuzzy sets and systems, 280 (2015) 107-132. http://dx.doi.org/ 10.1016/i.fss.2015.02.007

[20] G.W. Wei, Hesitant fuzzy prioritized operators and their application to multi attribute decision making, Knowledge-Based Systems 31 (2012) 176-182. http://dx.doi.org/10.1016/j.knosys. 2012.03.011

[21] G.X. Wang, P. Shi, Y.Y. Xie, Y. Shi, Two-dimensional discrete fuzzy numbers and applications, Information Sciences, 326 (2016) 258-269. http://dx.doi.org/10.1016/j.ins.2015.07.045

[22] G.C. Fan, D.H. Zhong, F. Yan, P. Yue, A hybrid fuzzy evaluation method for curtain grouting efficiency assessment based on AHP method extended by D numbers, Expert Systems with Applications, 44 (2016) 289-303. http://dx.doi.org/10.1016/j.eswa.2015. 09.006

[23] J.F. Chen, H.N. Hsieh, Q.H. Do, Evaluating teaching performance based on fuzzy AHP and comprehensive evaluation approach, Applied Soft Computing 28 (2015) 100-108. http://dx.doi.org/10.10 16/j.asoc. 2014.11 .050

\section{AUTHORS}

Hong Ye is a lecturer at School of Information Science and Technology, Dalian Maritime University, China. Her current research interests include Information Management, Distributed Computing and Software Engineering (e-mail: yehong@dlmu.edu.cn).

This work is supported in part by National Natural Science Foundation of China under Grant No.61173034, the Fundamental Research Funds for the Central Universities under Grant No.3132015046, and the Teaching Reform Project of Dalian Maritime University under Grant No.2014Y12. Submitted 07 November 2015. Published as resubmitted by the authors 05 December 2015. 